\title{
Correction to: Self-frequency shift and nonlinear interaction of equilibrium and pulsating solutions in the presence of linear and nonlinear gain, spectral filtering, and intrapulse Raman scattering
}

\author{
Ivan M. Uzunov ${ }^{1} \cdot$ Todor N. Arabadzhiev ${ }^{1} \cdot$ Zhivko D. Georgiev $^{2}$
}

Published online: 11 March 2019

(c) Springer Science+Business Media, LLC, part of Springer Nature 2019

\section{Correction to: Opt Quant Electron (2015) 47:2969-2981 https://doi.org/10.1007/s11082-015-0184-4}

In the original publication, the second author name was misspelt. The correct name is given in this Correction.

Publisher's Note Springer Nature remains neutral with regard to jurisdictional claims in published maps and institutional affiliations.

The original article can be found online at https://doi.org/10.1007/s11082-015-0184-4.

Todor N. Arabadzhiev

tna@tu-sofia.bg

1 Department of Applied Physics, Technical University Sofia, 8 Kl. Ohridski Blvd., 1000 Sofia, Bulgaria

2 Department of Theoretical Electrical Engineering, Technical University Sofia, 8 Kl. Ohridski Blvd., 1000 Sofia, Bulgaria 